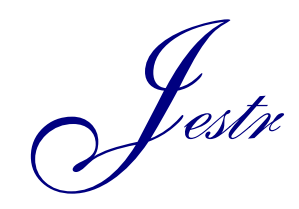

Research Article

www.jestr.org

\title{
Hydraulic System Design of Hydraulic Actuators for Large Butterfly Valves
}

\author{
Ye HUANG ${ }^{1, *}$, Changsheng LIU ${ }^{1}$ and Shiongur Bamed ${ }^{2}$ \\ ${ }^{1}$ School of Mechanical Engineering, Zhejiang Industry Polytechnic College, Shaoxing 312000, Zhejiang, China \\ ${ }^{2}$ University of Windsor, 401 Sunset Avenue, Windsor, ON, N9B 3P4, Canada
}

Received 15 May 2014; Accepted 19 September 2014

\begin{abstract}
Hydraulic control systems of butterfly valves are presently valve-controlled and pump-controlled. Valve-controlled hydraulic systems have serious power loss and generate much heat during throttling. Pump-controlled hydraulic systems have no overflow or throttling losses but are limited in the speed adjustment of the variable-displacement pump, generate much noise, pollute the environment, and have motor power that does not match load requirements, resulting in low efficiency under light loads and wearing of the variable-displacement pump. To overcome these shortcomings, this article designs a closed hydraulic control system in which an AC servo motor drives a quantitative pump that controls a spiral swinging hydraulic cylinder, and analyzes and calculates the structure and parameters of a spiral swinging hydraulic cylinder. The hydraulic system adjusts the servo motor's speed according to the requirements of the control system, and the motor power matches the power provided to components, thus eliminating the throttling loss of hydraulic circuits. The system is compact, produces a large output force, provides stable transmission, has a quick response, and is suitable as a hydraulic control system of a large butterfly valve.
\end{abstract}

Keywords: large butterfly valve, actuator, hydraulic system, spiral swinging hydraulic cylinder, design

\section{Introduction}

A butterfly valve has a simple structure, is convenient to operate, allows good flow regulation, and provides a good seal, and is widely used in petroleum, chemical, shipbuilding, metallurgy, pharmacy, electric power (such as hydropower and nuclear power), and other industries [1] [2]. In recent years, the control requirements of butterfly valves have increased with improvements in industrial process control automation and production efficiency, especially in high- temperature, high-pressure, inflammable, explosive, and toxic environments. These requirements have demanded the actuator of the butterfly valve to be small in size, light in weight, highly efficient, and highly reliable, and require little energy to run. However, large pipes and butterfly valves are used in practice. Control actuators and hydraulic systems should thus be further developed for large butterfly valves.

2. Analysis of the hydraulic control mode of the hydraulic actuator of a butterfly valve

To satisfy control requirements, the current configuration of large butterfly valves has an independent control system and hydraulic station. At present, there are three basic types of control systems for butterfly valves as described in this section [1] [2] [3] [4] [5].

\subsection{Valve-controlled hydraulic system}

A valve-controlled hydraulic system for a butterfly valve uses a commonly available motor and quantitative pump circuit, as shown in Figures 1 and 2. The system comprises a filter 1, relief valve 2, fixed-displacement pump 3, one-way valve 4 , accumulator 5 , hydraulic cylinder 6 , electrohydraulic proportional valve 7 , electro-hydraulic servo valve 9 , and filter 8 , where the numbers correspond to the labels in the figures. The electro-hydraulic proportional valve or electro-hydraulic servo valve regulates and controls the speed of the cylinders. Accumulators moderate the impact, absorb vibrations and open or close the butterfly valve in an emergency. A proportional valve is cheaper than a servo valve, but the servo valve has a faster dynamic response. Both circuits provide a rapid response and accurate control.

There are three disadvantages of the hydraulic control mode. First, the working environment of the servo valve is severe, and oil pollution can readily cause the failure of servo valve. Second, the valve-controlled system requires a large hydraulic tank, which limits its application in a small space; the servo valve has a large throttling loss, resulting in a serious power loss; and throttling of the servo valve generates heat in the system, requiring the system to be equipped with a cooling device because the servo valve is sensitive to temperature changes. Third, the servo valve is difficult and expensive to manufacture, and maintenance of a hydraulic system is difficult when the system fails [1] [2].

\footnotetext{
*E-mail address:huangye10@163.com

ISSN: 1791-2377 @ 2014 Kavala Institute of Technology. All rights reserved.
} 


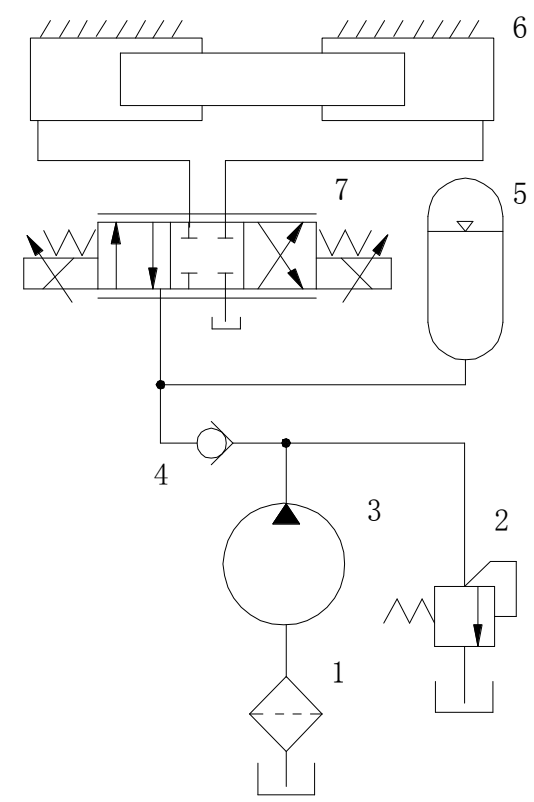

Fig. 1. Hydraulic system for proportional-valve control

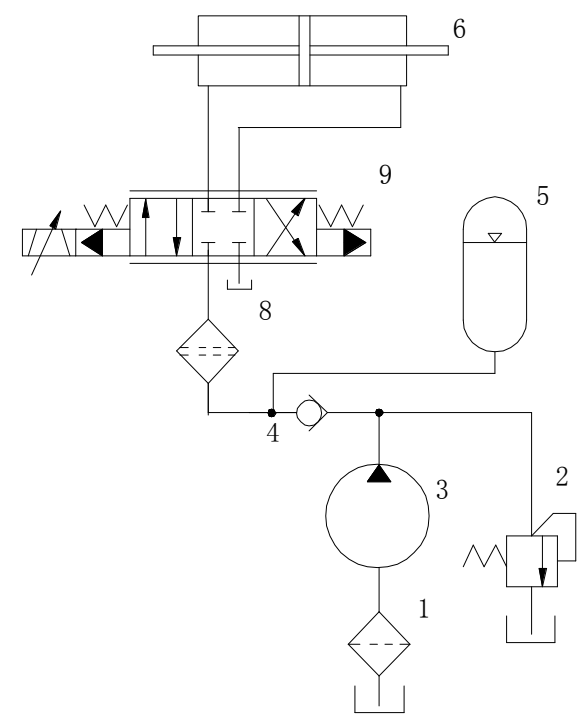

Fig. 2. Hydraulic system for servo-valve control

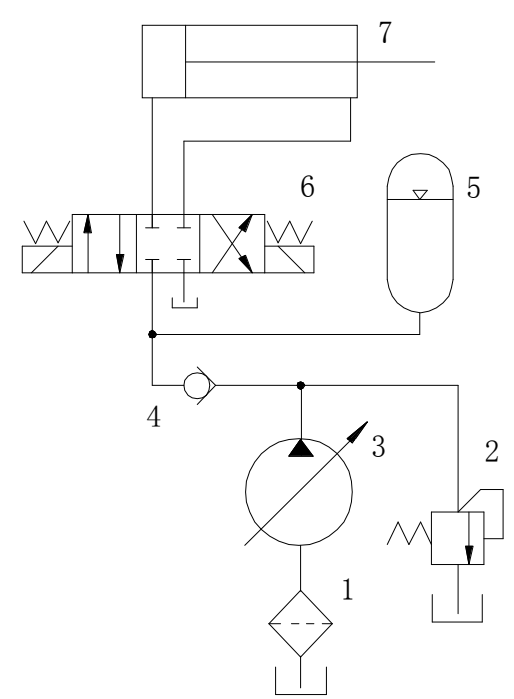

Fig. 3. Hydraulic system for pump control

\subsection{Pump-controlled hydraulic system}

A pump-controlled hydraulic system for a butterfly valve is shown in Figure 3. The system uses a commonly available motor and variable-displacement pump. Pressure oil produced by a pump 3 passes through a one-way valve 4 and reversing valve 6 , and enters the oil cylinder 7 , where the numbers refer to labels in the figure. The system depends on the variable-displacement pump adjusting the flow rate and the operational speed of the cylinder. The variabledisplacement pump varies its output flow by changing the angle of an inclined plate, so as to control the speed of the cylinder. The circuit has no overflow or throttling loss, has high efficiency, and can be used in a large power system. However, the system also has its disadvantages [4]. First, the angular range of the inclined plate of the variable pump is limited. The range of adjustment of the cylinder speed is thus limited and the variable-displacement pump generates much noise and is prone to polluting the working environment. Second, the rotational speed of the motor is constant under various conditions, yet the load on the system usually varies. The power provided by the motor thus does not match the power needed by components, and efficiency is low for light loads, which wastes energy and induces wear of the variable-displacement pump.

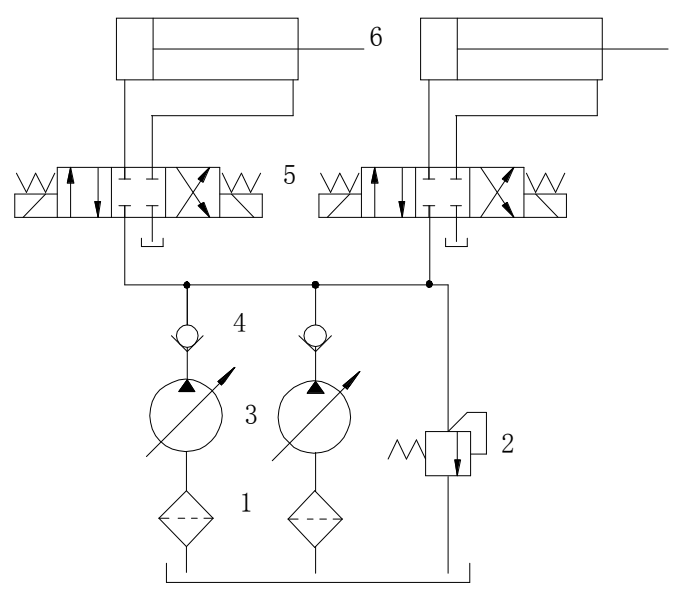

Fig. 4. Hydraulic system for several cylinders

If there are several butterfly valves, a concentrate hydraulic station is used as shown in Figure 4. The hydraulic system adopted two constant pressure variable pumps as power source, one is in spare. The two pumps need to work together when butterfly valves rotate at the same time.

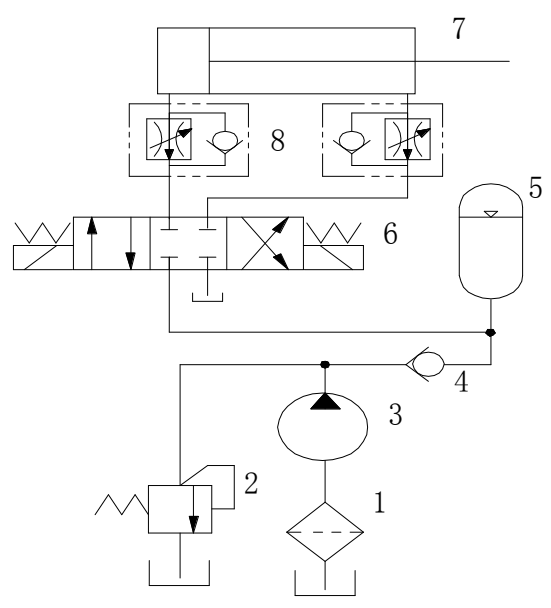

Fig. 5. Hydraulic system for accumulator control 


\subsection{Accumulator hydraulic control system}

An accumulator-controlled hydraulic system for a butterfly valve is shown in Figure 5. After the pump stops operation, the pressure oil of the accumulator passes through a reversing valve 6 and flow regulator valve 8 , and enters an oil cylinder 7, where the numbers refer to labels in the figure. A flow regulator valve adjusts the cylinder speed. At the same time, the accumulator provides auxiliary energy to the system, and the system thus only needs a small pump. Butterfly valves that do not frequently open and close, so as to reduce energy loss, employ this type of circuit [5]. If the hydraulic cylinder needs a high flow rate and high output force, then the system needs to be equipped with a larger accumulator that provides greater pressure. This design is clearly not suitable for large butterfly valves.

\section{Design of a hydraulic control system for the actuator of a large butterfly valve}

The three hydraulic control systems described above are mainly used in a butterfly valve system of medium size. A large butterfly valve requires large output torque and high control performance. If the hydraulic systems described above are used, the power consumption will be high and the control performance will not meet the requirements of application. Therefore, in view of control of a large butterfly valve, this article outlines a hydraulic system of servo motor and quantitative pump control, where the actuator employs a spiral swinging hydraulic cylinder, as shown in Figure 6.

\subsection{Design of the hydraulic system}

Figure 6 shows the components of the hydraulic system for the large butterfly valve as a servo motor 1 , bidirectional quantitative pump valve 2 , fill oil valve 3 , hydraulic lock 4 , fill oil pressure tank 5 , relief valve 6 , electromagnetic directional valve 7 , accumulator 8 , and a rotary hydraulic cylinder incorporating a screw 9.

The working principle of the system is that as pressure oil enters the upper (left) cavity of the spiral swinging hydraulic cylinder, the hydraulic output shaft turns to the right, oil in the lower (right) chamber enters the quantitative pump 2, and the shortage fraction oil of the inlet of pump 2 is supplied by supplement oil tank 5 passing by filling oil valve. Similarly, if the output shaft of the spiral swinging hydraulic cylinder turns to the left, quantitative pump 2 inverses and pressure oil enters the bottom (right) chamber of the hydraulic cylinder 9. As the liquid filling valve (hydraulically controlled check valve) 3 opens at the same time, redundant oil in the upper cavity of the hydraulic cylinder 9 returns to the pressure tank 5 . The hydraulic lock 4 protects against overloading. When the motor 1 loses electrical power and the variable pump 3 stops operating, the hydraulic lock 4 keeps the hydraulic cylinder 9 at a median position. Because the system needs only a small amount of oil when it runs normally, it does not need a large fuel tank, and the system can be made smaller in size. The whole system uses a programmable logic controller (PLC) that has an uninterruptible power supply (UPS). In the absence of electrical power or in an emergency, with the aid of the UPS, the accumulator 8 provides pressure oil to the oil cylinder through the reversing valve, thus completing the opening or closing of the butterfly valve.

The stem angle position of the butterfly valve is detected by an angle sensor. A given signal is compared with the angle signal and a control instruction is generated. The controller (including the servo motor driver) outputs a rotary speed instruction to the servo motor. The servo motor then drives the hydraulic quantitative pump to rotate. When the valve stem rotates to a given position, the comparison signals that controller obtains is zero, the servo motor outputs zero speed, and the hydraulic pump no longer provides pressure oil. At that time, two hydraulic controlled check valves lock the hydraulic cylinder, ensuring that the hydraulic cylinder does not move under the action of an external force [6] [7].

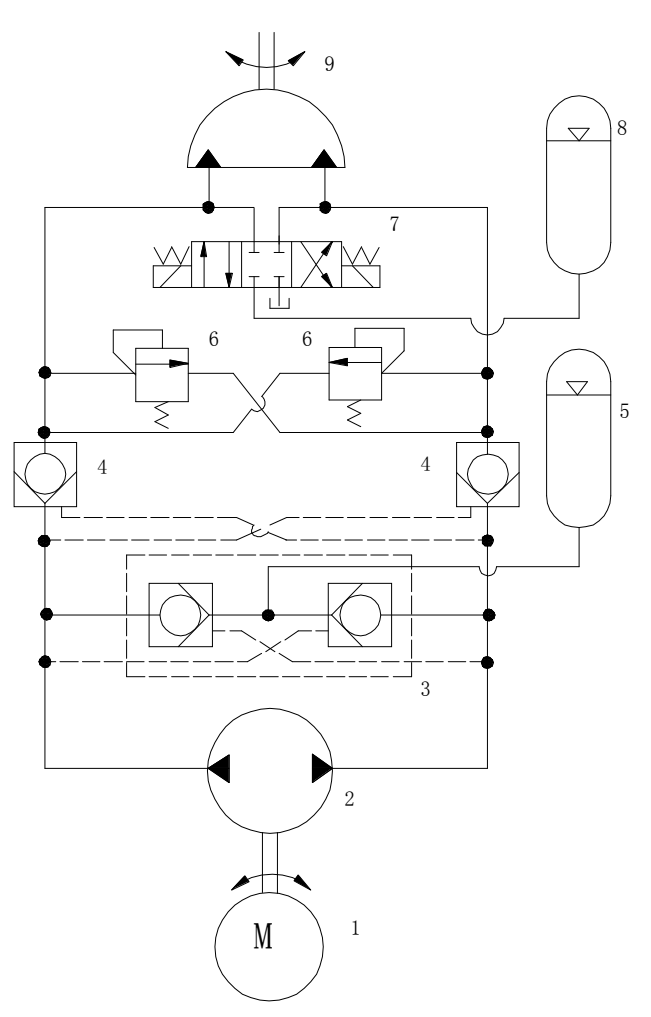

Fig. 6. Servo motor and pump control hydraulic system

This system embodies fully the characteristics of the AC servo motor. The motor can automatically change speed, direction, and torque, the power generated by the motor matches the power required by components at any time, and the system has high efficiency. This system overcomes disadvantages of the electro-hydraulic servo-valve control system, such as large throttling loss, a tendency to pollute the working environment, and high manufacturing cost [3], and avoids disadvantages of the variable-displacement pump control system, such as the narrow range of cylinder speed and power that do not match the load.

\subsection{Design and calculation of the spiral swinging hydraulic cylinder}

There are two main types of structures of hydraulic actuators that drive a butterfly valve plate to open and close: a gearrack rocking hydraulic cylinder and spiral swinging hydraulic cylinder. A gear-rack rocking hydraulic cylinder has large output torque, high efficiency, and long service life, but has a large axial dimension, requires a large installation space, and is subject to interior leaking[8] [9] [10]. That the spiral swinging hydraulic cylinder has a spiral structure that converts the reciprocating movement of the piston into the reciprocating rotation of the output shaft via a helical gear, as shown in Figures 6. The spiral swinging 
hydraulic cylinder has advantages such as a compact structure, safe and reliable operation, a small installation space, accurate positioning, a large output torque and large rotary angle, and no internal leaking, and thus has a wide range of application.

The use of a gear-rack rocking cylinder requires other intermediate transmission parts such as a gear or fork, whereas the output shaft of the spiral swinging hydraulic cylinder joins the stem of the valve plate directly through the coupling.

Butterfly valves only need to rotate through approximately $90^{\circ}$ to open or close. Because the rotation angle is small, the piston requires a short stroke. Thus the design adopts single-stage spiral transmission, reducing the difficulty of manufacture and assembly. The DN1200 butterfly valve adopts a hard seal, has rotational torque $T_{n}=42730 \mathrm{Nm}$ and a stem diameter of $d_{0}=130 \mathrm{~mm}$, and takes $10 \mathrm{~s}$ to open or close [11].

\subsubsection{Calculation of the screw parameters}

The given value of the maximum working pressure of the system is $20 M P_{a}$. Figure 7 is a diagram of the rotary cylinder structure with the screw. Depending on the screw mechanism, the piston converts liquid pressure into rotation of the screw. The screw has a standard right-hand trapezoidal thread. The screw parameters are the major diameter, pitch diameter, minor diameter, lead, and pitch [12].

The selected screw material is $45 \mathrm{CrNiMoVA}$, which has high shear strength and is quenched at $860{ }^{\circ} \mathrm{C}$ and tempered at $460{ }^{\circ} \mathrm{C}$ to ensure its strength and dimensional stability. The selected nut material is $\mathrm{ZCuSn} 10 \mathrm{~Pb} 1$, which has good resistance to wear. The mechanical properties of the materials are shown in Table 1.

D

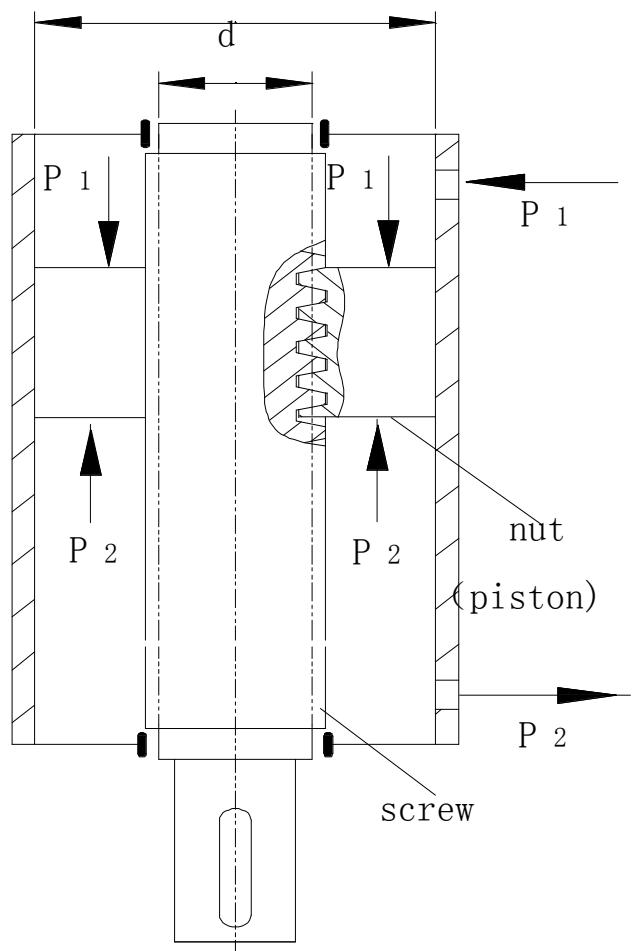

Table 1. Mechanical properties of materials

\begin{tabular}{c|c|c}
\hline material & $\begin{array}{c}\text { tensile strength } \\
\sigma_{b}\left(M P_{a}\right)\end{array}$ & $\begin{array}{c}\text { elastic limit } \\
\sigma_{s}\left(M P_{a}\right)\end{array}$ \\
\hline 45CrNiMoVA & 1470 & 1330 \\
\hline ZCuSn10Pb1 & 360 & 170 \\
\hline
\end{tabular}

According to the literature [12], the nominal diameter of the spiral under the condition that the screw pair undergoes pure shearing is estimated as follow:

$$
\begin{aligned}
& d \geq \sqrt[3]{\frac{16 T_{j}}{\pi[\tau]}} \\
& =\sqrt[3]{\frac{16 \times 1.2 \times 42730}{3.14 \times 0.6 \times 0.25 \times 1330 \times 10^{6}}} \\
& =0.10941(\mathrm{~m})=109.41(\mathrm{~mm})
\end{aligned}
$$

Here $T_{J}$ is the calculated torque $(\mathrm{mm})$, which is calculated as $T_{J}=K T_{n}$, where $T_{n}$ is the maximum load torque and $K$ is the correction coefficient; we select $K=1.2 .[\tau]$ is the allowable shear stress $\left(M P_{a}\right)$, which is taken as $0.6 \times 1 / 4$ times the yield strength [12], that is $[\tau]=\sigma_{s} \times 0.6 \times 0.25$. Considering the stem diameter to be joined and following the national standard, we select a large screw diameter $\mathrm{d}_{1}=160 \mathrm{~mm}$.

Furthermore, according to the national standard, we select the other parameters of the screw as shown in Table 2.

We take the nut screw laps $n_{0}=8$. The nut (piston) height is calculated as follow:

$H=n_{0} P=8 \times 16=128 m m$

The literature [12] gives the screw lead as follow:

$\mathrm{L}=n P=\pi d_{1} \tan \lambda$

Where $n$ is the alignment pole number of the screw.

Formula (3) shows that the bigger the lead $L$, the bigger the helix angle $\lambda$. The theoretical analysis of trapezoidal screw transmission is that the output torque increases with the spiral angle, but in practical application, the structure become larger with an increase in the helical angle of the spiral swinging hydraulic cylinder. However, manufacturing becomes more difficult as the helix angle increases. Considering the problems, we select the number of thread lines $n=40$.

The helix lead angle is calculated as follow:

$$
\lambda=\arctan \frac{n P}{\pi d_{1}}=\arctan \frac{40 \times 16}{\pi \times 160}=49^{\circ}
$$

Using formula (3), we calculate the spiral lead is $L=640 \mathrm{~mm}$. Because a butterfly valve only rotates through $90^{\circ}$ when opening or closing, the effective stroke for the hydraulic cylinder is selected as $L / 4$, that is $160 \mathrm{~mm}$ and this conforms to the national standard. The screw parameters are shown in Table 2.

Fig. 7. Swinging cylinder structure 
Table 2. Screw parameters

\begin{tabular}{c|c|c}
\hline name & symbol & value \\
\hline major diameter & $d_{1}$ & $160 \mathrm{~mm}$ \\
\hline pitch diameter & $d_{2}$ & $152 \mathrm{~mm}$ \\
\hline minor diameter & $d_{3}$ & $142 \mathrm{~mm}$ \\
\hline pitch & $P$ & $16 \mathrm{~mm}$ \\
\hline lead & $L$ & $640 \mathrm{~mm}$ \\
\hline nut height & $H$ & $130 \mathrm{~mm}$ \\
\hline helix lead angle & $\lambda$ & $49^{\circ}$ \\
\hline cylinder stroke & $L / 4$ & $160 \mathrm{~mm}$
\end{tabular}

3.2.2 Calculation of the mechanical efficiency of the screw

According to the force diagram shown in Figure 8 and the static equilibrium principle, the force equations of the screw are shown as follows:

$F_{P}=F_{1}+F_{2}=N \cos \lambda+N \mu \sin \lambda$

$N=F_{P} /(\cos \lambda+\mu \sin \lambda)$

Where $\lambda$ is the helix angle ( $\mathrm{deg}$ ), $\mu$ is the coefficient of friction, and $\alpha$ is the tooth profile angle. For a T-thread, $\alpha=30^{\circ}$ and the circumferential force rotating of the screw and the resistance are respectively given by followings:

$T_{1}=N \sin \lambda$

$T_{2}=N \mu \cos \lambda$

The torque equation is shown as follow:

$T=T_{1}-T_{2}=N(\sin \lambda-\mu \cos \lambda)$

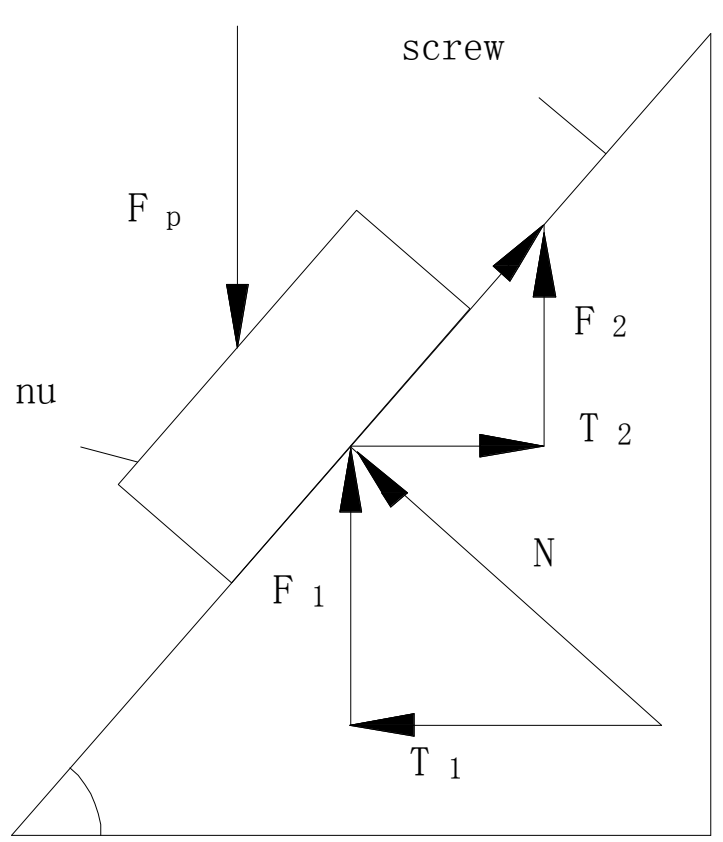

Fig. 8. Screw forces

The output torque of the spiral swinging hydraulic cylinder $M(\mathrm{Nm})$ is calculated as follow:
$M=T \frac{d_{0}}{2}$

Where $d_{0}$ is the average diameter, which is calculated according to the pitch diameter of the screw here.

Combining formulas (5)-(9) with formula (10) leads to

$M=F_{p} \times \frac{\sin \lambda-\mu \cos \lambda}{\cos \lambda+\mu \sin \lambda} \times \frac{d_{0}}{2}$

$=\frac{F_{p} d_{0}}{2} \times \frac{\tan \lambda-\mu}{1+\mu \tan \lambda}=\frac{\Delta P S d_{0}}{2} \tan (\lambda-\rho)$

Where $\mu$ is the vice friction angle of the screw, according to the spiral vice materials, we select $\mu=0.08$. $\Delta P$ is the pressure difference between two oil cavities of the hydraulic cylinder $\left(M P_{a}\right)$, which can be calculated according to the equation $F_{p}=\triangle P S \cdot \mathrm{S}$ is the effective compression area of the piston $\left(\mathrm{mm}^{2}\right)$. According to the structure and national standard, we select the piston diameter $D=250 \mathrm{~mm}$ (i.e., cylinder diameter), the protrusion of the rod diameter $d=140 \mathrm{~mm}, \mathrm{~S}$ can be calculated as follow:

$S=\frac{\pi}{4}\left(D^{2}-d^{2}\right)=35796 \mathrm{~mm}^{2}$

According to the mechanical design manual [12], the theoretical output torque of the spiral swinging cylinder is given by the following:

$M_{0}=\frac{\Delta P S d_{0}}{2}$

Considering the tooth profile angle $\alpha$, the equivalent friction angle of the screw is shown as follow:

$\rho_{v}=\arctan \frac{\mu}{\cos (\alpha / 2)}=\arctan \frac{0.08}{\cos 15}=4.6^{\circ}$

The mechanical efficiency of the rotary cylinder is calculated as follow:

$$
\begin{aligned}
& \eta=0.98 \times \frac{M}{M_{0}}=0.98 \times \frac{\tan \left(\lambda-\rho_{v}\right)}{\tan \lambda} \\
& =0.98 \times \frac{\tan (49-4.6)}{\tan 49}=0.8342
\end{aligned}
$$

Where 0.98 stands for the bearing efficiency.

The output angular velocity of the oil cylinder is $\omega=$ $0.0785(\mathrm{rad} / \mathrm{s})$, then the output (input) flow of the hydraulic cylinder is calculated by the following:

$$
\begin{aligned}
& Q=\frac{60 \omega L S}{2 \pi} \\
& =\frac{60 \times 0.0785 \times 640 \times 35796}{2 \pi} \\
& =538824 \mathrm{~mm}^{3} / \mathrm{s}=34.38 \mathrm{~L} / \mathrm{min}
\end{aligned}
$$


We select back pressure $P_{2}=0.8 M P_{a}$. Using formula (11), the actual output torque of the hydraulic cylinder can be calculated as follow:

$$
\begin{aligned}
& M=\frac{\Delta P S d_{0}}{2} \tan \left(\lambda-\rho_{v}\right) \\
& =\frac{(20-0.8) \times 35796}{2} \tan (49-4.6)=48122 \mathrm{Nm}
\end{aligned}
$$

$M>T_{n}$, this result satisfies the requirement of the load.

\section{Conclusion}

This paper analyzed traditional hydraulic control circuits of butterfly valves, designed a closed hydraulic control system in which an AC servo motor drives a quantitative pump that controls a spiral swinging hydraulic cylinder, and analyzed and calculated the structure and parameters of the spiral swinging hydraulic cylinder. The following conclusions are drawn from the results of the study.

(1) Traditional hydraulic control systems of a butterfly valve have large energy consumption and low output torque, a narrow range of adjustment of the cylinder speed, and power of the electric motor that does not match the load. Traditional systems are thus not suitable for the control of large butterfly valves.
(2) A new system adopts an AC servo motor and uses a quantitative pump to drive an actuator. Using an electric motor to change speed, direction, and torque instead of the three traditional hydraulic control systems, the change in speed of the AC servo motor can control the rate of a quantitative pump, and the speed of the servo motor can be adjusted according to the needs of the system, allowing the motor power to match perfectly the power needed by components. The system eliminates the throttling loss of hydraulic circuits, saves energy, and has a greatly simplified hydraulic circuit.

(3) A quantitative pump produces little noise, generates little pollution, has low requirements for the oil filter, is easy to maintain, has low manufacturing and use costs, and extends the system lifetime.

(4) The new system has a simpler composition, has fewer hydraulic circuits, and is lightweight, and all elements can be integrated into one body, greatly reducing the system volume and making the system more convenient to use and install. For a closed system, there is no external fuel tank, which greatly reduces oil pollution and protects the environment.

(5) A single-stage spiral swinging hydraulic cylinder has many advantages such as compact structure, easy of manufacture, safe and reliable operation, small occupying space, accurate positioning, large output torque and rotary angle, no interior leaking, high efficiency, and ease of control.

\section{References}

[1]. DA Jin, LI Qipen, DING Fan, "Application of Electrohydraulic Servo Technology on Butterfly Valve", MACHINE TOOL \& HYDRAULICS, 1 (41), 2013, pp.1-3.

[2]. Liu Hui, Ge Liang,Yan Jun, "Numerical Simulation of Hydraulic Control System for Marine Butterfly Valve", Chinese Journal of Ship Research, 4(7), 2012, pp.97-101.

[3]. QUAN Long, "The Present Status and Latest Progress of Electrohydraulic Control Technology of Multi-actuators Used in Construction Machinery", Hydraulics Pneumatics \& Seals, 1, 2010, pp.40-44.

[4]. WANG Cheng-bin, "The Simulation and Test Study of Constant Speed Servo Pump-Controlled Differential Cylinder", Hydraulics Pneumatics \& Seals, 8, 2014, pp. 12-14.

[5]. Li-hua Huang, "Energy storage tank of hydraulic control butterfly valve hydraulic control system improvement", China's high-tech enterprises, 6, 2008, pp.46-53.

[6]. Huang Junhao, Yang Peng, Ji Huiqun, Shi Guanglin, "Research of an Electro-hydraulic actuator Based on Direct Driving Servo Motor", Fluid Power Transmission and Control, 5(46) ,2011,pp.5-9.
[7]. ZHANG Koi-pen, KE Jion, LlU Huon-lon, WANG Guo-zhi, "Simulation on Characteristics of Direct Drive Electric-hydraulic Actuator for Valve", Hydraulics Pneumatics \& Seals, 12, 2013, pp.9-11.

[8]. ZHAO Xian piong, CHEN Zhihong, LIU Yilun, "R\&D on hydraulic rotary actuator based on virtual prototype technology", Journal of Chongqing University, 4(37), 2014, pp.71-76.

[9]. Li Songbai, Liu Yilun, Xie Shiguan, Liu Weitao, "Modeling and Dynamic Simulation of Rotary Hydraulic Cylinder based on Pro/E and Adams", Journal of Mechanical transmission, 11(34), 2010, pp.34-37.

[10]. LI Song-bai, LIU Yi-lun, LIU Wei-tao, "Optimal design for screw rotary cylinder's radial clearance", Journal of Central South University (Science and Technology), 5(43), 2012, pp. 1710-1716.

[11]. ZHANG Qingshuang, Butterfly valve samples manual of Beijing valve group. CHINA MACHINE PRESS, Beijing, 2010.

[12]. Xu Hao, Mechanical design manual, CHINA MACHINE PRESS, Beijing, 2012. 